\begin{tabular}{c} 
journal homepage: http://ijiemjournal. uns.ac.rs/ \\
International Journal of Industrial \\
Engineering and Management \\
Volume $12 /$ No 4 / December $2021 / 253-261$ \\
\hline
\end{tabular}

Original research article

\title{
Selection of sustainable suppliers in the oil and gas industry using fuzzy multi-criteria decision-making methods
}

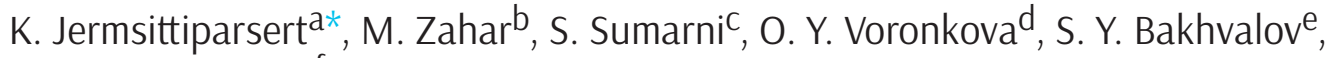 \\ and R. Akhmadeev ${ }^{f}$ \\ a College of Innovative Business and Accountancy, Dhurakij Pundit University, Bangkok, Thailand; \\ ${ }^{b}$ Social Security Centre of Excellence (SOSCOE), School of Business Management (SBM), College of Business, Universiti Utara \\ Malaysia, Kedah, Malaysia; \\ c Universitas Sebelas Maret, Surarta, Jawa Tengah, Indonesia; \\ ${ }^{d}$ Altai State University, Barnaul, Russia; \\ e Kazan Federal University, Kazan, Russia;

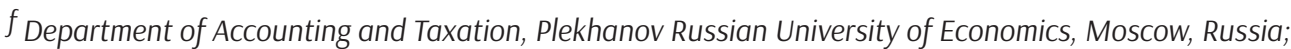

A B STRACT

Due to the globalization of competition in various fields, suppliers must have the best performance by creating different competitive advantages. In addition, the oil and gas industry has lots of sustainability issues in the supply phase. Accordingly, this study provides a comprehensive framework for ranking and selecting sustainable suppliers in the oil and gas industry. In this research, first, using the fuzzy analytical network process method, the indicators of selecting stable suppliers are ranked. Next, by applying the Electre method, the most appropriate suppliers are chosen. Numerical results show that the quality indicators of materials purchased from suppliers and commitment to contracts were ranked first and second among all criteria. Moreover, the efficiency of the proposed framework is approved by comparing with the real-world situation.
ARTICLE INFO

Article history:

Received May 25, 2021

Revised July 21, 2021

Accepted August 4, 2021

Published online November 2, 2021

Keywords:

Supplier Selection;

Stable Supplier;

Fuzzy Network Analysis;

Electre Method

${ }^{*}$ Corresponding author:

Kittisak Jermsittiparsert

amolajou@gmail.com

\section{Introduction}

Customers' demand for high-quality and rapid services has increased pressure on companies that never existed before, which has held back enterprises from doing all the work alone. In the current competitive market, economic and production enterprises need the management and monitoring of related extra-organizational resources and dealing with the organiza- tion of internal resources. This is mainly to achieve competitive advantage(s), aiming at earning a larger market share [1-4]. Accordingly, activities such as supply and demand planning, material preparation, product manufacturing and planning, goods maintenance service, controlling the inventory, distribution, delivery, and customer service, all of which were carried out at the corporate level before, are now transferred to the supply chain level. One of the important 
issues in supply chain management is evaluating and selecting efficient suppliers, which leads to creating a competitive advantage and improving the organization's performance. This is important when considering several discount suppliers. One of the important factors for survival in today's highly competitive environment is reducing production costs. Choosing the right suppliers can significantly reduce purchasing costs and increase the competitiveness of the organization. In most industries, the cost of raw materials and components of the product is a large part of the cost of the product $[5,6]$.

The nature of such decisions is usually complex and lacks structure, and many quantitative and qualitative performance criteria such as quality, price, flexibility, and delivery time must be considered to determine the most appropriate supplier [7-9].

Overall, selecting a suitable supplier is a key issue in a supply chain [10-13]. Choosing an appropriate supplier who can meet customers' needs by providing a proper volume of high-quality products at a reasonable price at a proper time is one of the most necessary activities for creating a proper supply chain. In fact, deciding about the supplier plays a considerable role in companies' logistic management and production, and many experienced enterprises believe that supplier selection is the most important activity of an organization [14].

Suppliers are an integral part of a company and can have various impacts on organizational performance. These effects necessitate the revision of supplier selection methods. Currently, the need to specialize businesses and customized services has united organizations in order to find strategic allies and form supply chains. In these situations, supplier selection in line with the long-term objectives and strategies of the organization not only increases efficiency but also leads to higher effectiveness of activities in the organization's productivity [15-20]. Therefore, the selection of an inappropriate supplier can cause serious challenges for the organization. In some cases, the lack of quality of a suitable commodity has led to the death of people in oil companies. Without a doubt, retaining production ability, protecting the lives of the personnel, and increasing the lifespan of equipment, factories, and large national assets depends on the selection of quality and suitable suppliers. Today, strategic cooperation with suppliers seems necessary in order to supply goods at the desired quality level and decrease the delivery time in oil and gas projects. Supplier selection should be based on the opinions of project beneficiaries so that the selected ones could meet the projects' needs [21]. Supply Chain
Management (SCM) can link operations and production management with maintaining the level of production in oil and gas exploiting companies by having a proper process for supplying goods and optimizing the supply process with the help of focused inventory management.

Given the above, the main issue of this research is to find a suitable framework for evaluating suppliers in the oil and gas industry. This framework organizes the various features for ranking suppliers and provides a solution to make it easier to find suppliers.

In this regard, given the fact that SCM requires complete mastery of the process, from material purchasing to the production section and from purchasing raw materials to sales and after-sales services, supplier selection can be an interesting and thoughtprovoking topic for research. With this background in mind, the present study aimed to evaluate the selection of sustainable suppliers in the oil and gas industry.

\section{Research Background}

Employer satisfaction achievement is one of the goals of construction companies in the competitive atmosphere of project implementation. In this regard, one of the main employer satisfaction factors is the quality implementation of the project in a timely manner and at a reasonable cost with regard to other performance indicators. Therefore, supplier selection plays a fundamental role in achieving these objectives and has become crucial for organizational success. Purchasing-related decisions have become more important with an increase in purchasing significance. In fact, the higher companies' dependence on their suppliers, the direr the consequences of their wrong decisions. Meanwhile, the supplier selection is more sensitive in oil and gas projects due to expensive equipment, the necessity to have the required standards and safety, and the importance of time of arrival of this equipment to the project given the losses caused by daily delays in the project (especially in joint oil fields) in the country [6]. The selection of a set of suppliers is a crucial factor for organizational success. Recently, special attention has been paid to the supplier selection process. Selection and practical assessment of suppliers is an important responsibility that should be considered by purchasing managers. The importance of supplier selection is due to its impact on the elements related to the end products of organizations [14].

The issue of potential supplier selection and eval- 
uation is a multi-criteria group decision-making problem, which requires the assessment of the degree of data uncertainty, the number of decision-makers, and the nature of the criteria. Supplier and contractor performance assessment in a supply chain is a process carried out to measure the analyses and manage their performance to reduce costs and risks and constantly improve value creation and operations. Overall, recognizing the performance and evaluating the organization's existing performance clarifies the stages of their development and improvement [22].

New companies deal with extreme competition owing to the acceleration of the processes of economic globalization. Many companies increase the quality of their products while decreasing their costs to attract more customers. Since the raw material supplier plays an important role in this process, companies need to find proper suppliers and make great collaborations with them. Various criteria are involved in supplier selection, some of which are in conflict with each other (e.g., quality and cost). Therefore, supplier selection is identified as a multicriteria decision-making problem [23]. Today, oil and gas industries face serious challenges such as the entrance of foreign suppliers and increased activities of domestic suppliers due to organizations' joining in global trade. Therefore, oil and gas industries should increase their attention to their suppliers' status to improve productivity in this dynamic environment due to the significant role of suppliers' performance in achieving the mission of oil and gas extraction and production in organizations [24].

Chakraborty et al. [5] assessed to resolve the uncertainty involved in the decision-making process of supplier selection with the application of distributor numbers. A relatively new Multi-Criteria DecisionMaking (MCDM) technique in the form of Measurement Alternatives And Ranking According to Compromise Solution (MARCOS) was later employed for ranking of a set of alternative suppliers. Stojanović and Puška [6] investigated growing countries' logistical performances and identified which country has the best conditions for establishing a regional logistic center. For this study, they used relevant data from Logistics Performance Index (LPI). Ali et al. [25] assessed the interval-valued Pythagorean fuzzy set. They explored the Complex Interval-Valued Pythagorean Fuzzy Einstein Weighted Geometric (CIVPFEWG), Complex Interval-Valued Pythagorean Fuzzy Einstein Ordered Weighted Geometric (CIVPFEOWG) operators and utilized their special cases. Moreover, an MCDM technique is explored based on the elaborated operators using the Com- plex Interval-Valued Pythagorean Fuzzy (CIVPF) information.

By comparing the research items in the literature, oil and gas exploitation companies are no exception and need a suitable assessment regarding commodity supplier selection. We aimed to evaluate the key factors involved in the supplier selection process with this background in mind.

\section{Supply Chain Management}

"A supplier is a natural or legal person who offers a product within the framework of the relevant laws, regulations, and licenses and may act as a trader with the manufacturer. The supplier can act as a seller in the system if he has a membership in Iran Code and achieves a national ID for the product following receiving a membership."

"A purchaser is a natural or legal person in need of purchasing a product, who registers as "buyer" in the system and submits a request for purchasing one or several products. The purchaser may be the final user or a part of goods distribution network intermediaries acting as a supplier. In both assumptions, purchasing must be carried out through registration on the system as a purchaser and after receiving a password."

Today, SCM is one of the infrastructural foundations for the implementation of electronic business in the modern world. In addition, the current global competition has necessitated the provision of a variety of products based on customers' demands. Customer demand for high quality and rapid service provision has increased pressures on companies that never existed before. This has prevented enterprises from doing their work independently of others. In the current competitive market, economic and production enterprises need the management and monitoring of related extra-organizational resources and dealing with the organization of internal resources. This is mainly to achieve competitive advantage(s), aiming at earning a larger market share. Accordingly, activities such as supply and demand planning, material preparation, product manufacturing and planning, goods maintenance service, controlling the inventory, distribution, delivery, and customer service, all of which were carried out at the corporate level before, are now transferred to the supply chain level. A key issue in the supply chain is managing and controlling the coordination of all activities. In fact, the SCM phenomenon enables customers to receive reliable and fast service with quality products at minimum cost [17].

Some of the brief and comprehensive definitions 
of supply chain and SCM include: the supply chain includes all activities related to the production of goods from raw material (extraction) to delivery of products to the end consumer and information flow related to them. The supply chain generally comprises the flow of all information, products, materials, and funds between different stages of creating and selling a product to the end-user. There are also two other flows in this area, namely information, and finance flows [14, 21].

SCM comprises three main processes, including:

1. Information management

2. Logistic management

3. Relationship management

\section{Main Phases of SCM}

First phase

The conceptual design of the first phase is indicative of the construction strategy. This phase determines how the organization is managed by creating an image for the future and a structure for implementation. A special organizational model is required for the processes of the first phase, which can be different in each organization. Nevertheless, a conceptual model is the main issue at this phase, which can confirm and implement the other two phases. This phase is primarily car- ried out to comprehend details related to costs and recognize the system and benefits of SCM [10, 26, 27].

Second Phase: Designing and Testing the Details

This phase can be implemented simultaneously with the first and third phases, meaning that the details are designed, and the solutions are concomitantly tested in the real world. At this phase, it is recommended that changes be made in the organization's structure, and these modifications are taken into account in the implementation of the system to support the design of a new supply chain.

\section{Third Phase: Implementation}

In this phase, following the second phase, the implementation schedule of long periods of operation and changes in the system are carried out in order to generate facilities. In this study, the statistical population included commodity management specialists and experts of procurement projects in oil and gas exploitation companies. In total, 10 participants were included for data analysis.

\section{Research Methodology}

The proposed research methodology is presented in Figure 1.

In this research, we used few techniques to test research questions. The outputs of the questionnaires were assessed with the following methods and

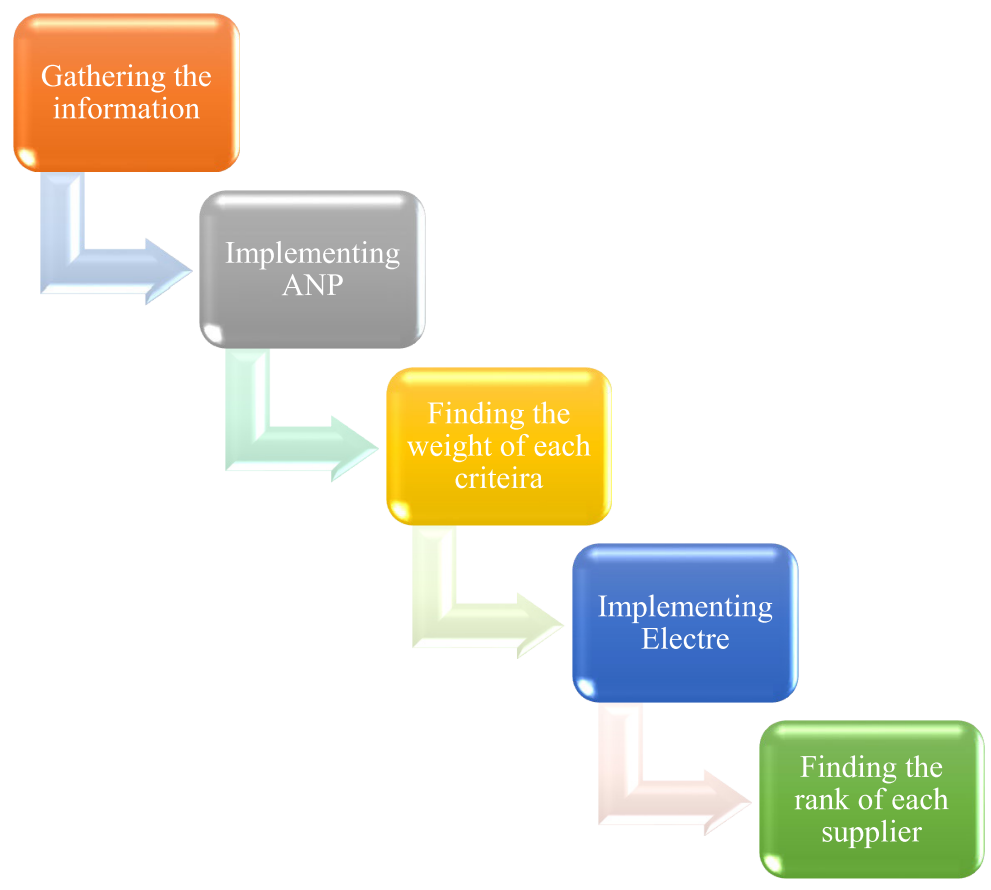

Figure 1. Proposed research methodology 


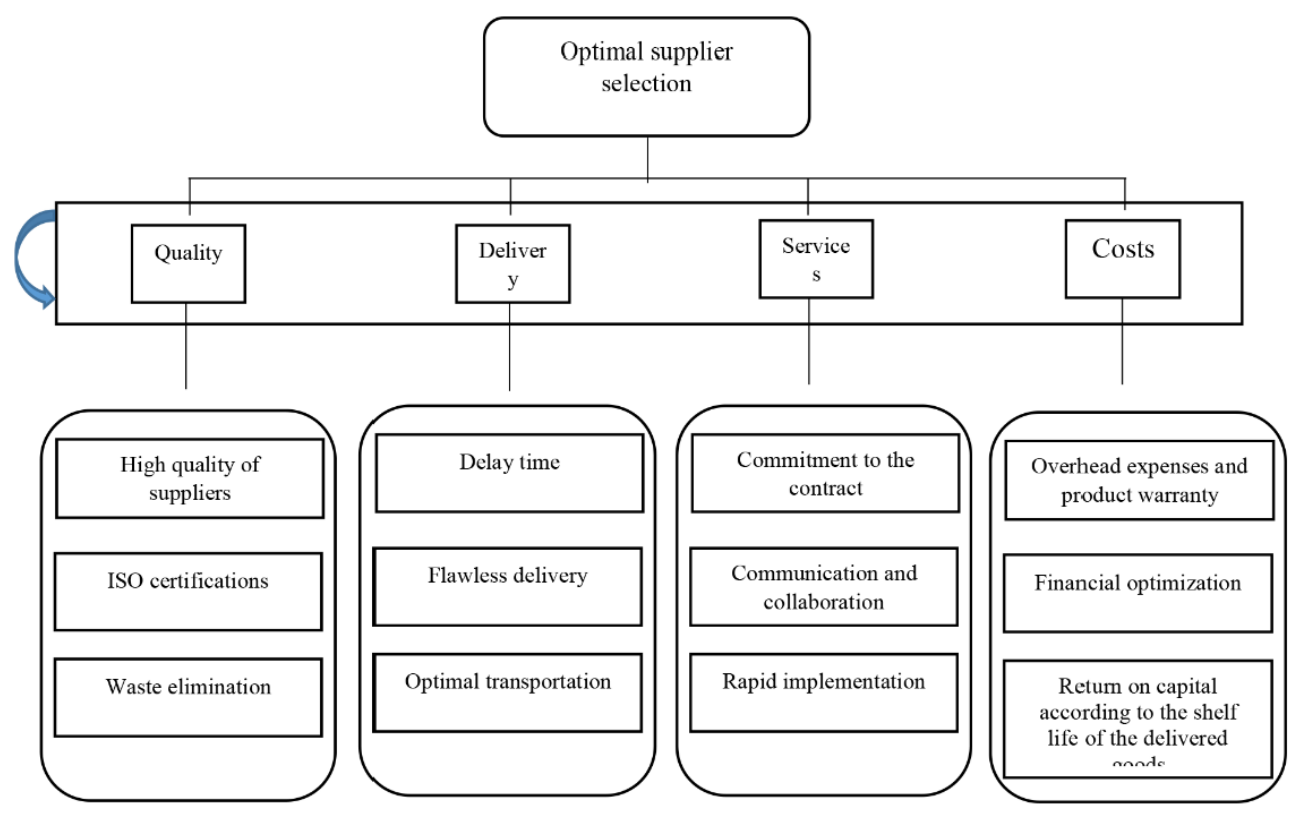

Figure 2. Conceptual model of the research

provide answers to the test questions: the indicators of goods supplier selection were identified using the Electre 2 approach and fuzzy Analytical Network Process (ANP). The main reason for choosing the ANP method compared to similar methods is that this method is known among research experts, and also the collection of the required information is easy to do. The steps of ANP is as follows:

Step 1. Providing pairwise comparisons

Step 2. Providing the super-matrix

Step 3. Calclulating the limited super-martix

Step 4. Providing the weight of each criterion and sub-criteria

\subsection{Conceptual Model}

The conceptual model of the research and its indicators are obtained by modeling from the literature. The studied indicators are inspired by [3-6,21] and illustrated in Figure 2.

\subsection{The Electre Method}

The Electre method was first introduced by Benayoun in 1966 and then developed by researchers such as Rou and Van delf [28]. In this method, all options are assessed using non-ranking comparisons, which leads to the elimination of ineffective options. All these stages are planned based on a harmonious set and an asymmetric set, and this feature has resulted in recognition of the Electre method as a coordination analysis technique. There are different versions of the Electre method, such as Electre 1, 2, 3, and 4, which are different in terms of the type of mathematical operations and problems that can be solved by the mentioned techniques [28].

The main reason for choosing the Electre method compared to similar methods is that this method, due to the design of the system for comparing options, is somewhat similar to the ANP method and is highly compatible with it. Also, the Electre method is mentioned as an efficient method in finding the best option in the literature.

\section{Electre Method Stages}

Stage 1. Formation of a decision matrix

We formed the decision matrix based on the number of criteria and options and estimated values of options for different criteria, as shown below:

$$
\mathrm{X}=\left[\begin{array}{ccc}
x_{11} & \ldots & x_{1 n} \\
\ldots & \ldots & \ldots \\
x_{m 1} & \ldots & x_{m n}
\end{array}\right]
$$

Where $\mathrm{x}_{\mathrm{ij}}$ shows the performance of the $i$-th option relative to the $j$-th criterion.

Stage 2. Unscaling the decision matrix

At this stage, criteria with different dimensions were turned into dimensionless criteria. In this regard, unscaling was carried out using the equation below:

$$
r_{i j}=\frac{x_{i j}}{\sqrt{\sum_{i=1}^{m} x_{i j}^{2}}}
$$


Stage 3. Determining the Criteria Weight Matrix

At this stage, the importance coefficient vector of the criteria was determined based on the importance coefficients of different criteria for decision-making. The weight of the criteria can be determined by methods such as the AHP or Shannon entropy. We also used the ANP results in the present research.

Stage 4. Determining the normalized weighted decision matrix

The weighted decision matrix was obtained from the unscaled decision matrix coefficient against the weight of criteria.

$$
v i j=w j * r i j \quad j=1,2, \ldots, n ; i=1,2, \ldots, m
$$

Stage 5. Formation of $S_{k e}$ and Dke criteria set

For each pair of $\mathrm{k}$ and e options, the set of criteria was divided into two $S_{k e}$ and Dke subsets. The $S_{k e}$ subset is a set of criteria where the $\mathrm{k}$ option is preferred over the e option, and its complementary set is $\mathrm{D}_{\mathrm{ke}}$ subset. The $S_{k e}$ criteria set for positive and negative criteria is defined as follows:

$$
\begin{aligned}
& S_{k e}=\left\{j \mid V_{k j} \geq V_{e j}\right\} \\
& S_{k e}=\left\{j \mid V_{k j} \leq V_{e j}\right\}
\end{aligned}
$$

The $\mathrm{D}_{\mathrm{ke}}$ set for the positive and negative criteria is defined as follows:

$$
\begin{aligned}
& D_{k e}=\left\{j \mid V_{k j}<V_{e j}\right\}=J-S_{k e} \\
& D_{k e}=\left\{j \mid V_{k j}>V_{e j}\right\}=J-S_{k e}
\end{aligned}
$$

\section{Stage 6. Agreement matrix formation}

The agreement matrix is a square matrix, the dimension of which is the number of options. Each entry of the matrix is called the agreement index between two options. The value of the index is obtained from the sum of the weights of the criteria in the Ske set. In other words, the $\mathrm{k}$ and e options should be compared to estimate the agreement index $\left(\mathrm{C}_{\mathrm{ke}}\right)$, and its value is obtained from the sum of the weight of criteria, where the $\mathrm{k}$ option is preferred over the e options. Mathematically, $\mathrm{C}_{\mathrm{ke}}$ is calculated using the equation below:

$$
C_{k e}=\sum_{j \in S_{k e}} W_{j}
$$

In this regard, $\mathrm{C}_{\mathrm{ke}}$ shows the level of superiority of the $\mathrm{k}$ option over the e option, and its value varies from zero to one.
Stage 7. Disagreement matrix formation

The disagreement matrix is a square matrix, the dimension of which is the number of options. Each entry of the matrix is called the disagreement index between two options, and its value is calculated using the equation below:

$$
d_{k e}=\frac{\max _{j \in D_{k e}}\left|V_{k j}-V_{e j}\right|}{\max _{j \in I}\left|V_{k j}-V_{e j}\right|}
$$

\section{Stage 8. Formation of Matrix (F)}

In the sixth stage, we expressed the method of calculation of $\mathrm{C}_{\mathrm{ke}}$. In this section, a specific value was determined for $\mathrm{C}_{\mathrm{ke}}$ known as the agreement threshold shown by the symbol of $\mathrm{C}^{-}$. The agreement threshold is obtained from estimating the mean of $\mathrm{C}_{\mathrm{ke}}$ (entries of the agreement matrix). Mathematically, the agreement threshold was calculated using the equation below

$$
\bar{C}=\sum_{k=1}^{m} \sum_{e=1}^{m} \frac{C_{k e}}{m(m-1)}
$$

In this regard, $\mathrm{F}$ is formed based on the threshold value. If $\mathrm{C}_{\mathrm{ke}}$ is larger than $\mathrm{C}^{-}$, the superiority of the $\mathrm{k}$ option over the e option is accepted. Otherwise, the $\mathrm{k}$ option has no superiority over the e option. Therefore, the entries of $\mathbf{F}$ are determined using the equation below:

$$
f_{k e}=\left\{\begin{array}{ll}
1 & c_{k e} \geq \bar{c} \\
0 & c_{k e}<\bar{c}
\end{array}\right\}
$$

\section{Stage 9. Formation of (G)}

In this stage, $\mathrm{G}$ was formed similar to $\mathrm{F}$, for which we first calculated the threshold of $\mathrm{d}^{-}$by estimating the mean of $\mathrm{D}_{\mathrm{ke}}$ (entries of the disagreement matrix). Mathematically, $\mathrm{d}^{-}$is calculated using the equation below:

$$
\bar{d}=\sum_{k=1}^{m} \sum_{e=1}^{m} \frac{d_{k e}}{m(m-1)}
$$

As shown in stage 7, the lower the value of dke, the better. This is mainly due to the fact that the level of disagreement shows the superiority of the k option over the e option. If $\mathrm{d}_{\mathrm{ke}}$ is larger than $\mathrm{d}^{-}$, the level of disagreement is high and cannot be overlooked. Therefore, the entries of $\mathrm{G}$ are estimated as follows:

$$
g_{k e}=\left\{\begin{array}{ll}
1 & d_{k e}>\bar{d} \\
0 & d_{k e} \leq \bar{d}
\end{array}\right\}
$$

Each member of $\mathrm{G}$ shows the dominant relationship between the options. 
Stage 10- Formation of $(\mathrm{H})$

In this section, $(\mathrm{H})$ is obtained from multiplying every single entry of $(F)$ into entries of $(G)$.

$$
h_{k e}=f_{k e} \cdot g_{k e}
$$

Stage 11. Best option selection

In this section, $(\mathrm{h})$ reveals the minor preferences of the options. For instance, if hke is equal to one, the superiority of the $\mathrm{k}$ option over the e option is acceptable in both agreement and disagreement modes (i.e., its superiority was above the agreement threshold and its disagreement was below the disagreement threshold). Nevertheless, the $\mathrm{k}$ option still has the chance to be dominated by other options. In this respect, an option that is more dominant than being dominated should be chosen, and this issue can be used to rank the options.

\section{Results}

This section presents the numerical results obtained from the implementation of the proposed decision-making approach. In Table 1, the prioritiza- tion of criteria is presented by ANP, and the ranking of sub-criteria is presented in Table 2.

After determining the weight of each criterion, the results of the Electre method were analyzed. The mentioned method can be used to evaluate the superiority of different options. In this study, the evaluated options were mentioned in the form of $\mathrm{A} 1, \mathrm{~A} 2$, and A3. Table 3 presents the threshold results in the ELECTRE method.

In order to validate the research results, the output was compared with the opinions of research experts, and their final opinion was asked. Based on this, the research experts confirm the output, and as a result, the validity of the results is confirmed. Also, in order to analyze the sensitivity of the results, in addition to the proposed approach, the desired model with random weights for the indicators has been implemented three times. The results are presented in Table 4.

The results presented in Table 4 show that when the ANP method is used, option A1 is selected as the superior, but when random weight is used, the other options are selected as the superior. This indicates that the use of the ANP method can provide different results than other possible scenarios.

Table 1. Prioritization of the weight of the criteria and the weight of the sub-criteria using ANP

\begin{tabular}{ccc}
\hline Criteria & Weight & Rank \\
\hline Quality & 0.31619 & 1 \\
Delivery & 0.28874 & 2 \\
Services & 0.19338 & 4 \\
Costs & 0.20169 & 3 \\
\hline
\end{tabular}

Table 2. Sub-criteria ranking in ANP

\begin{tabular}{lcc}
\hline Sub-criteria & Weight & Rank \\
\hline High quality of suppliers & 0.572158 & 1 \\
ISO certifications & 0.105147 & 12 \\
Waste elimination & 0.294603 & 7 \\
Time of delay & 0.426323 & 4 \\
Flawless delivery & 0.298816 & 8 \\
Optimal transportation & 0.2839 & 9 \\
Commitment to the contract & 0.531599 & 2 \\
Communication and collaboration & 0.144601 & 11 \\
Quick launch & 0.329934 & 6 \\
Overhead costs and product warranty & 0.515613 & 3 \\
Financial optimization & 0.14877 & 10 \\
Return on capital based on the shelf life of delivered products & 0.348536 & 5 \\
\hline
\end{tabular}


Table 3. Evaluation of threshold results with the method's conditions

\begin{tabular}{cccc}
\hline & $A_{1}$ & $A_{2}$ & $A_{3}$ \\
\hline$A_{1}$ & - & 0 & 0 \\
$A_{2}$ & 0 & - & 0 \\
$A_{3}$ & 0 & 0 & - \\
\hline
\end{tabular}

Table 4. Sensitivity analysis of the results

\begin{tabular}{ccccc}
\hline & ANP-Electre & $\begin{array}{c}\text { Random weight (1)- } \\
\text { Electree }\end{array}$ & $\begin{array}{c}\text { Random weight (2)- } \\
\text { Electree }\end{array}$ & $\begin{array}{c}\text { Random weight (3)- } \\
\text { Electree }\end{array}$ \\
\hline A1 & 0.40 & 0.35 & 0.35 & 0.30 \\
A2 & 0.35 & 0.40 & 0.45 & 0.30 \\
A3 & 0.25 & 0.25 & 0.20 & 0.4 \\
\hline
\end{tabular}

\section{Discussion and Conclusion}

According to the results, the quality index had the highest importance. High-quality, specialized equipment is very important for suppliers in exploiting companies since the lack of quality goods has caused irreparable damage in several accidents. In the next step, it is important to determine the delivery time for the applicants due to maintaining the production capacity and optimizing the production process. Since the cost of supplying goods is generally based on the lowest cost in tenders, having a standard cost of supplying goods is more important than having a very low cost. Meanwhile, suppliers must meet their obligations regarding after-sales service and repairs of delivered devices over the years. Therefore, choosing a quality and stable manufacturing company in supplying goods is essential. In this regard, our findings are in line with the results obtained by Freeman and Chen [12] and Peng et al. [24], showing that views are almost similar regarding goods supply in various organizations.

A more complete and accurate analysis of the results obtained in this study shows that the use of the ANP method in determining weights can provide completely different results from other methods. However, the ANP method is highly accepted by research experts due to its popularity. Also, the Electre technique can provide very accurate results for ranking suppliers in the oil and gas industry due to the separation of options and their pairwise comparison. This case is considered the most important achievement of this research.

It is suggested that oil and gas exploitation companies provide technical and quality approval to the production companies and the bidders in order to deliver appropriate quality according to the framework of the Standards Committee of the Southern Oil Fields Company. Nevertheless, this has not been implemented in the Oil and Gas Exploitation Company, and companies are not required to comply with this principle. Therefore, it is suggested that the Standards Committee consider a special score and rank for all applicant companies based on the standards in question, and companies should be required to comply with these standards.

- It is suggested that in order to provide quality goods and based on the appropriate delivery time, a quality evaluation committee be formed in the presence of the applicant's office, which is also not observed in companies.

- It is suggested to invite suppliers with excellent records to help increase the technical knowledge of purchasing experts by holding conferences and seminars to gain sufficient expertise in selecting suppliers.

- It is suggested that purchasing experts be required to participate continuously in permanent and international industry and service exhibitions.

\section{Funding}

This research did not receive any specific grant from funding agencies in the public, commercial, or not-for-profit sectors. 


\section{References}

[1] A. Bhattacharya, J. Geraghty, and P. Young, "Supplier selection paradigm: An integrated hierarchical QFD methodology under multiple-criteria environment," Applied Soft Computing, vol. 10, no. 4, pp. 1013-1027, 2011, doi: 10.1016/j.asoc.2010.05.025

[2] P. Ceryno, L. Santos, S. Felipe, K. Katja, and Y. Gökhan, "Supply chain risk management: a content analysis approach," Int. J. Ind. Eng. Manag., vol. 4, no. 3, pp.141$150,2013$.

[3] J. Chai, and W.N. Eric, "Decision-making techniques in supplier selection: Recent accomplishments and what lies ahead," Expert Systems with Applications, vol. 140, 112903, 2020, doi: 10.1016/j.eswa.2019.112903

[4] Z. Chen, X. Ming, T. Zhou, and T. Chang, "Sustainable supplier selection for smart supply chain considering internal and external uncertainty: An integrated rough-fuzzy approach," Applied Soft Computing, vol. 87, 106004, 2020, doi: 10.1016/j.asoc.2019.106004

[5] S. Chakraborty, R. Chattopadhyay, and S, Chakraborty, "An integrated D-MARCOS method for supplier selection in an iron and steel industry," Decision Making: Applications in Management and Engineering, vol. 3, no. 2, pp. 49-69, 2020, doi: 10.31181/dmame2003049c

[6] I. Stojanović, and A. Puška, "Logistics Performances of Gulf Cooperation Council's Countries in Global Supply Chains," Decision Making: Applications in Management and Engineering, vol. 4, no. 1, pp. 174-193, 2021, doi: 10.31181/dmame2104174s

[7] N. Jain, and A. R. Singh, "Sustainable supplier selection under must-be criteria through Fuzzy inference system," Journal of Cleaner Production, vol. 248, 119275, 2020, doi: 10.1016/j.jclepro.2019.119275

[8] O. Lavastre, A. Gunasekaran, and A. Spalanzani, "Supply Chain Risk Management in French companies," Decision Support Systems, vol. 52, no. 4, pp. 828-838, 2012, doi: 10.1016/j.dss.2011.11.017

[9] S. K. Mangla, P. Kumar, M. K. Barua, "Risk Analysis in Green Supply Chain Using Fuzzy AHP Approach, A Case Study," Resources, Conservation and Recycling, vol. 104, part B, pp. 375-390, 2016, doi: 10.1016/j.resconrec.2015.01.001

[10] F. Ecer, and P. Draga, "Sustainable supplier selection: A novel integrated fuzzy best worst method (F-BWM) and fuzzy $\mathrm{CoCoSo}$ with Bonferroni $(\mathrm{CoCoSo} \mathrm{B})$ multi-criteria model," Journal of Cleaner Production, vol. 266, 121981, 2020, doi: 10.1016/j.jclepro.2020.121981

[11] F. Liu, and H. Hai, "The voting analytic hierarchy process method for selecting supplier," Int.J. Production Economics, vol. 97, pp. 308-317, 2005, doi: 10.1016/j.jppe.2004.09.005

[12] J. Freeman, and T. Chen, "Green supplier selection using an AHP-Entropy-TOPSIS framework," Supply Chain Management, vol. 20, no. 3, pp. 327-340, 2015, doi: 10.1108/SCM-04-2014-0142

[13] S. M. Pahlevan, S. M. S. Hosseini, and A. Goli, "Sustainable supply chain network design using products' life cycle in the aluminum industry," Environ Sci Pollut Res, 2021, doi: 10.1007/s11356-020-12150-8

[14] R. Guido, M. Giovanni, P. Enrico, and S. Vittorio, "A framework for food traceability: case study-Italian extravirgin olive oil supply chain, " Int. J. Ind. Eng. Manag., vol. 11, no. 1, pp. 50-60, 2020, doi: 10.24867/IJIEM-2020-1-252

[15] J. J. Peng, T. Chao, Z. Wen-yu, Z. Shua, and W. Jian-qiang, "An integrated multi-criteria decision-making framework for sustainable supplier selection under picture fuzzy environment," Technological and Economic Development of Economy, vol. 26, no. 3, pp. 573-598, 2020, doi: 10.3846/ tede. 2020.12110
[16] S. Wan, G. Xu, J. Dong, "Supplier selection using ANP and ELECTRE II in interval 2-tuple linguistic environment," Information Sciences, vol. 385, no. C, pp. 19-38, 2017, doi: 10.1016/j.ins.2016.12.032

[17] M. Thenarasu, K. Rameshkumar, S. P. Anbuudayasankar, G. Arjunbarath, and P. Ashok, "Development and selection of hybrid dispatching rule for dynamic job shop scheduling using multi-criteria decision making analysis (MCDMA)," Int. J. Qual. Res., vol. 14, no. 2, pp. 487-504, 2020, doi: 10.24874/IJQR14.02-10.

[18] Q. Wu, H. Ren, W. Gao, J. Ren, and C. Lao, "Profit allocation analysis among the distributed energy network participants based on Game-theory", Energy, vol. 118, pp.783-794, 2017, doi: 10.1016/j.energy.2016.10.117

[19] S. Yin, and T. Nishi, "A Supply Chain Planning Model with Supplier Selection under Uncertain Demands and Asymmetric Information," in 47th CRIP Conference on Manufacturing Systems, Procedia CRIP, vol 17, pp. 639644, 2017, doi: 10.1016/j.procir.2014.01.109

[20] X. Zhao, D. Atkins, M. Hu, and W. Zhang, "Revenue Management under Joint Pricing and Capacity Allocation Competition," European Journal of Operational Research, vol. 257, no. 3, pp. 957-970, 2017, doi: 10.1016/j. ejor.2016.08.025

[21] A. Goli, E. B. Tirkolaee, and G. W. Weber, "A Perishable Product Sustainable Supply Chain Network Design Problem with Lead Time and Customer Satisfaction using a Hybrid Whale-Genetic Algorithm," in Logistics Operations and Management for Recycling and Reuse. EcoProduction (Environmental Issues in Logistics and Manufacturing), P. Golinska-Dawson (eds). Berlin, Heidelberg: Springer, 2020, pp. 99-124, doi: 10.1007/978-3-642-33857-1_6.

[22] Y. Huang, G.Q. Huang, and X. Liu, "Cooperative Gametheoretic Approach for Supplier Selection, Pricing and Inventory Decisions in a Multi-level Supply Chain," in International Multi Conference of Engineers and Computer Scientists, China, Hong Kong, 2013.

[23] R. Narasimhan, S. Ttalluri, and D. Mendez, "Supplier evaluation and rationalization via data envelopment analysis: An empirical examination," Journal of supply chain management, vol. 37, no. 2, pp. 28-37, 2001, doi: 10.1111/j.1745-493X.2001.tb00103.x

[24] J. J. Peng, C. Tian, W. Y. Zhang, S. Zhang, and J. Q. Wang, "An integrated multi-criteria decision-making framework for sustainable supplier selection under picture fuzzy environment," Technological and Economic Development of Economy, vol. 26, no. 3, pp. 573-598, 2020, doi: 10.3846/ tede. 2020.12110

[25] Z. Ali, T. Mahmood, K. Ullah, and Q. Khan, "Einstein Geometric Aggregation Operators using a Novel Complex Interval-valued Pythagorean Fuzzy Setting with Application in Green Supplier Chain Management," Reports in Mechanical Engineering, vol. 2, no. 1, pp. 105-134, 2021, doi: 10.31181/rme2001020105t

[26] K. Rashidi, A. Noorizadeh, D. Kannan, K. Cullinane, "Applying the triple bottom line in sustainable supplier selection: A meta-review of the state-of-the-art," Journal of Cleaner Production, 2020, 122001, doi: 10.1016/j. jclepro.2020.122001

[27] S.W. Ryu, and K.K. Lee, "A stochastic inventory model of dual sourced supply chain with lead-time reduction," International Journal of Production Economics, vol. 81-82, pp.513-524, 2003, doi: 10.1016/S0925-5273(02)00294-3

[28] L. Botti, and N. Peypoch, "Multi-criteria ELECTRE method and destination competitiveness," Tourism Management Perspectives, vol. 6, pp. 108-113., 2013, doi: 10.1016/j. tmp.2013.01.001 